\title{
Treatment Outcome and Risk Factors Associated with Diffuse Axonal Injury in Patients with Moderate to Severe Head Injury
}

\author{
Moinay $\mathrm{KIM}^{1}$, Suk Kyung $\mathrm{HONG}^{2}$, Sang Ryong JEON ${ }^{1}$, Sung Woo ROH ${ }^{1}$, Seungjoo LEE ${ }^{1,3}$ \\ ${ }^{1}$ Asan Medical Center, University of Ulsan College of Medicine, Department of Neurological Surgery, Seoul, Republic of Korea \\ ${ }^{2}$ Asan Medical Center, University of Ulsan College of Medicine, Department of Surgery, Division of Trauma and Surgical Critical Care, Seoul, \\ Republic of Korea \\ ${ }^{3}$ Asan Medical Center, University of Ulsan College of Medicine, Department of Neurosurgery, Division of Neurosurgical Critical Care, Seoul, \\ Republic of Korea
}

Corresponding author: Seungjoo LEE rghree@amc.seoul.kr

\section{ABSTRACT}

AIM: To evaluate diffuse axonal injury (DAl) patients according to DAl stage to identify risk factors that may affect clinical outcome.

MATERIAL and METHODS: A total of 992 traumatic brain injury (TBI) patients visited our hospital between 2011 and 2016. Thirtyseven patients diagnosed with DAI were enrolled in this study and stratified by DAI stage: Stage I, 20 patients (54.1\%); Stage II, 4 patients (10.8\%); and Stage III, 13 patients (35.1\%).

RESULTS: The mean age and the median follow-up period were 45.43 years and 13 months, respectively. Patient demographic data and clinical findings on admission showed no differences according to DAl stage, except for the revised trauma score (RTS) $(p=0.026)$. In univariate analysis, stages I and II vs. III $(p=0.001)$ and stages I vs. II and III $(p=0.019)$, transfusion within 24 hours of visit $(p=0.033)$, shock or cardiac arrest $(p=0.006)$, traumatic subarachnoid hemorrhage $(T-S A H)(p=0.011)$, and subdural hematoma $(\mathrm{SDH})(\mathrm{p}=0.009)$ were significantly correlated with Glasgow outcome score (GOS). In multivariate analysis, DAI stage I and II vs. III $(p=0.005)$ and SDH $(p=0.040)$ were significant.

CONCLUSION: Clinically, Stage II was more correlated with Stage I, rather than stage III. Stage III showed a much poorer outcome compared to stages I and II. Magnetic resonance imaging (MRI) should be promptly performed in all TBI patients when a patient's level of consciousness and cranialcomputed tomography (CT) does not match, as there is a possibility of stage III DAI.

KEYWORDS: Brain injury, Diffuse axonal injury, Head trauma, Traumatic brain injury

ABBREVIATION: CI: Confidence intervals, CT: Computed tomography, DAl: Diffuse axonal injury, DWI: Diffusion-weighted imaging, FLAIR: Fluid attenuated inversion recovery, GCS: Glasgow coma scale, GOS: Glasgow outcome score, ICU: Intensive care unit, MRI: Magnetic resonance imaging, RTS: Revised trauma score, SDH: Subdural hematoma, SWI: Susceptibility-weighted imaging, TBI: Traumatic brain injury.

\section{INTRODUCTION}

$\mathrm{T}$ raumatic brain injury (TBI) is a major cause of disability and morbidity worldwide $(2,36)$. A wide spectrum of brain injuries and associated clinical issues can result after head trauma. Along this spectrum, diffuse axonal injury (DAl) is common and associated with very high morbidity and mortality (18). In addition, it is a key prognostic factor for neurologic and functional outcome $(12,40)$. The mechanism of DAI involves acceleration-deceleration forces along different
Moinay KIM (1) : 0000-0002-6443-7098

Suk Kyung HONG (1) : 0000-0001-5698-0122

Sang Ryong JEON (1) : 0000-0002-8340-7978
Sung Woo ROH (D) : 0000-0001-6562-4154

Seungjoo LEE (1) : 0000-0003-0641-3917 
axes that lead to direct damage of blood vessels and axons (11), and therefore is considered a shearing injury. Despite the clinical importance of DAl, early diagnosis remains a clinical challenge $(2,3)$.

DAl staging is based on anatomical location (12). Stage I involves DAI lesions confined to the lobar white matter or cerebellum. If these lesions involve the corpus callosum with or without lesions in the lobar white matter, it is classified asstage II. The presence of traumatic lesions in the brainstem is classified as stage III.

To date, researchers have focused on the association between characteristics of DAl and clinical outcome. Yet studies directly comparing outcome between patients with different stages of DAl are lacking and their results are often vague. Generally, stage III DAI patients are known to have apoor clinical outcome $(13,27,44)$, however, the outcome of stages I and II are less evident due to the conflicting results reported previously $(19,35)$.

Clinical factors associated with DAl outcome are unclear. The association between clinical outcome and the volume and number of DAl lesions has been verified by some studies $(28,38,48)$, but not others $(14,39)$. In addition, some parameters, including vital signs, laboratory data, transfusion, intracranial pressure management, and surgical management have not been extensively analyzed. Although some studies have investigated the value of the above parameters in predicting outcome, to our knowledge, few have focused on identifying risk factors related to DAl stage. Hence, we present a single institution retrospective analysis of DAl patients according to DAl stage to identify risk factors that may affect clinical outcome.

\section{- MATERIAL and METHODS}

\section{Patient Selection}

The records of 992 patients who were admitted to our hospital for head trauma between January 2011 and December 2016 were retrospectively reviewed. All patients with cranial computed tomography (CT) scan or magnetic resonance imaging (MRI) findings consistent with DAl as determined by certified neuroradiologists were included in this study. TBI patients were assessed upon admission by neurosurgeons using various scoring systems: the Glasgow coma scale (GCS) (42), injury severity score (ISS) (15), and revised trauma score (RTS) (6). Patients with GCS $\geq 14$ on admission were excluded. Six other patients were also excluded as follows: 3 expired on the day of admission and 3 were transferred to other hospitals due to a lack of intensive care unit (ICU) facilities. Finally, 37 patients were enrolled. A flow chart detailing the study enrollment is summarized in Figure 1.

Data regarding patient demographics (age, sex, and medical comorbidities), trauma mechanism, clinical parameters (GCS, ISS, and RTS scores, vital signs, laboratory data on admission, blood transfusion, shock or cardiac arrest, medical and surgical treatment details, length of hospital stay, ICU stay, and mechanical ventilation) and radiologic findings (number of DAl lesions, and associated traumatic findings) were recorded in each patient.

\section{Radiologic Evaluation-Cranial CT and MRI}

All TBI patients underwent a cranial CT scan on admission. Brain MRI was performed when the injuries observed on the CT scan could not explain the patient's decreased neurologic status or when DAl was suspected but the CT scan could not provide enough information. However, MRI was not performed in some patients due to a medical contraindication. T1-weighted, T2-weighted, and fluid attenuated inversion recovery (FLAIR) sequences were acquired in the axial, sagittal, and coronal planes; susceptibility-weighted imaging (SWI) and T2-weighted gradient echo (T2 GRE) sequences, which are sensitive in detecting hemorrhagic lesions, as well as diffusion-weighted imaging (DWI) were also obtained in all patients. The number of DAl lesions and associated traumatic findings on CT or MRI were reviewed and interpreted by 2 experienced neuroradiologists. Interobserver reliability was evaluated via data review by a third neuroradiologist who was blinded to the clinical information and previous interpretations. DAl was classified according to the staging system suggested by Gentry (Figure 2) (12). This system classifies DAl into 3 stages based on the presence of axonal injury in different anatomical locations: the gray-white matter interface in the cerebral hemispheres (stagel), corpus callosum (stage II), and brainstem (stage III). DAI staging was applied for each MRI sequence separately and for all sequences combined; the highest stage observed was assigned.

\section{Neuro-Intensive Care Management}

Thirty-three of the 37 study patients were initially admitted to ICU. They were intubated if there was evidence of decreased neurologic status $(\mathrm{GCS}<8)$ or respiratory distress. Patients were managed using a standard ICU protocol for ICP and cerebral perfusion pressure management (9): $30^{\circ}$ head of bed elevation, hyperventilation (target $\mathrm{P}_{\mathrm{CO} 2} 30-35 \mathrm{mmHg}$ ), and central venous pressure target of $0-5 \mathrm{mmHg}$. Blood pressure was managed to maintain mean arterial pressure $>70$ $\mathrm{mmHg}$. Transfusion was considered according to patient medical history, but usually administered as needed to maintain hemoglobin $>9 \mathrm{~g} / \mathrm{dL}$, prothrombin time $>50 \%$, and platelet count $>100,000 \mathrm{~g} / \mathrm{L}$. Mannitol was administrated if there was evidence of cerebral edema on CT or MRI scans. Surgical decisions for extraventricular drainage (EVD) or decompressive craniectomy were at the discretion of the attending staff when the patient deteriorated neurologically or showed worsening radiologic findings despite optimal medical treatment.

\section{Patient Assessment and Clinical Outcome}

To evaluate functional outcome, the Glasgow outcome score (GOS) was assessed on the patients' last visit to the hospital. In the GOS system, patients are stratified into 5 groups ranging from good recovery to death (17). These outcomes are dichotomized into favorable (GOS 4 and 5) and unfavorable (GOS 1, 2 and 3) groups. No surviving patients were lost to follow-up in this study. 
992 traumatic head injury patients admitted to hospital

(Between January 2011 and December 2016)

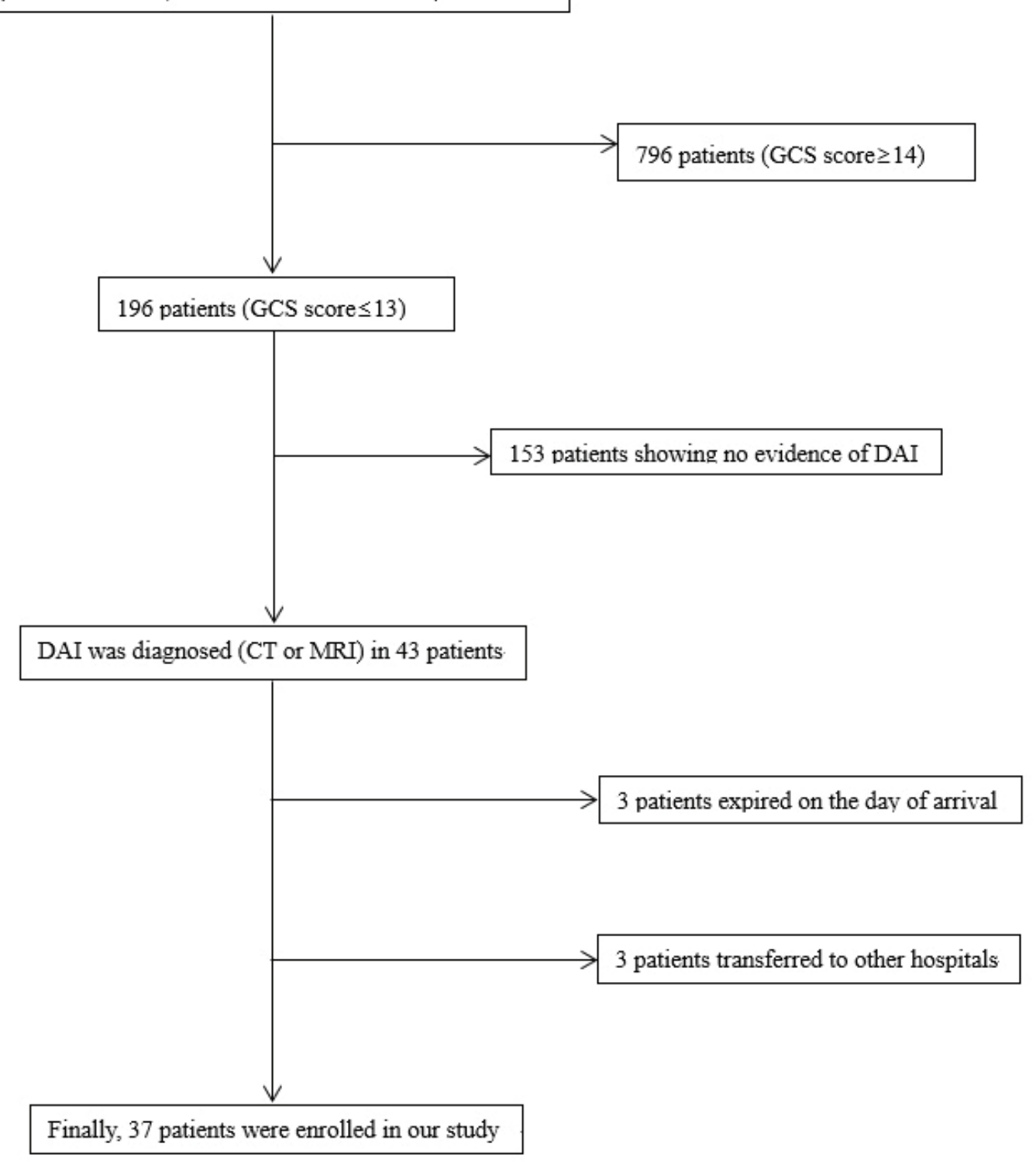

Figure 1: Flow chart showing patients admitted to our hospital during the study period. Inclusion and exclusion criteria are shown with a summary of the number of patients participating in our study. CT: computed tomography, DAl: diffuse axonal injury, GCS: Glasgow coma scale, MRI: magnetic resonance imaging.

\section{Statistical Analysis}

All statistical analyses were performed using SPSS software, version 21(SPSS, Inc., Chicago, IL, USA). The chi-square test or Fisher's exact test was used for comparison of categorical variables, and the Student's t-test or Kruskal-Wallis test for continuous variables. The relationship between DAl and clinical outcome was analyzed using univariate and multivariatelogistic regression models with dichotomized GOS (favorable or unfavorable) as the dependent variable. Significant factors identified by the univariate analysis additionally underwent multivariate logistic regression analysis with a stepwise selection method. All values are reported as a mean \pm standard deviation. $\mathrm{p}<0.05$ was considered significant. Precision of the estimates was assessed with $95 \%$ confidence intervals $(\mathrm{Cl})$.

\section{RESULTS}

Of the 992 patients who were admitted to our hospital for head trauma during the study period, 43 presented with GCS $\leq 13$ and diagnosed with DAI. Six patients from this group were not enrolled in the study: 3 expired in the acute phase and 3 transferred to other hospitals. Finally, 37 patients $(3.73 \%)$ were enrolled. The patients consisted of 28 men (75.68\%) and 9 women (24.32\%). Mean age was 45.43 years (range 16-83). Median follow-up was 13 months (interquartile range, 6-22).

Patients were stratified into 3 stages according to Gentry's DAl classification (12): 20 patients (54.05\%) were classified as stage I, 4 patients $(10.81 \%)$ as stage II, and 13 patients $(35.14 \%)$ as stage III. These groups were further analyzed 


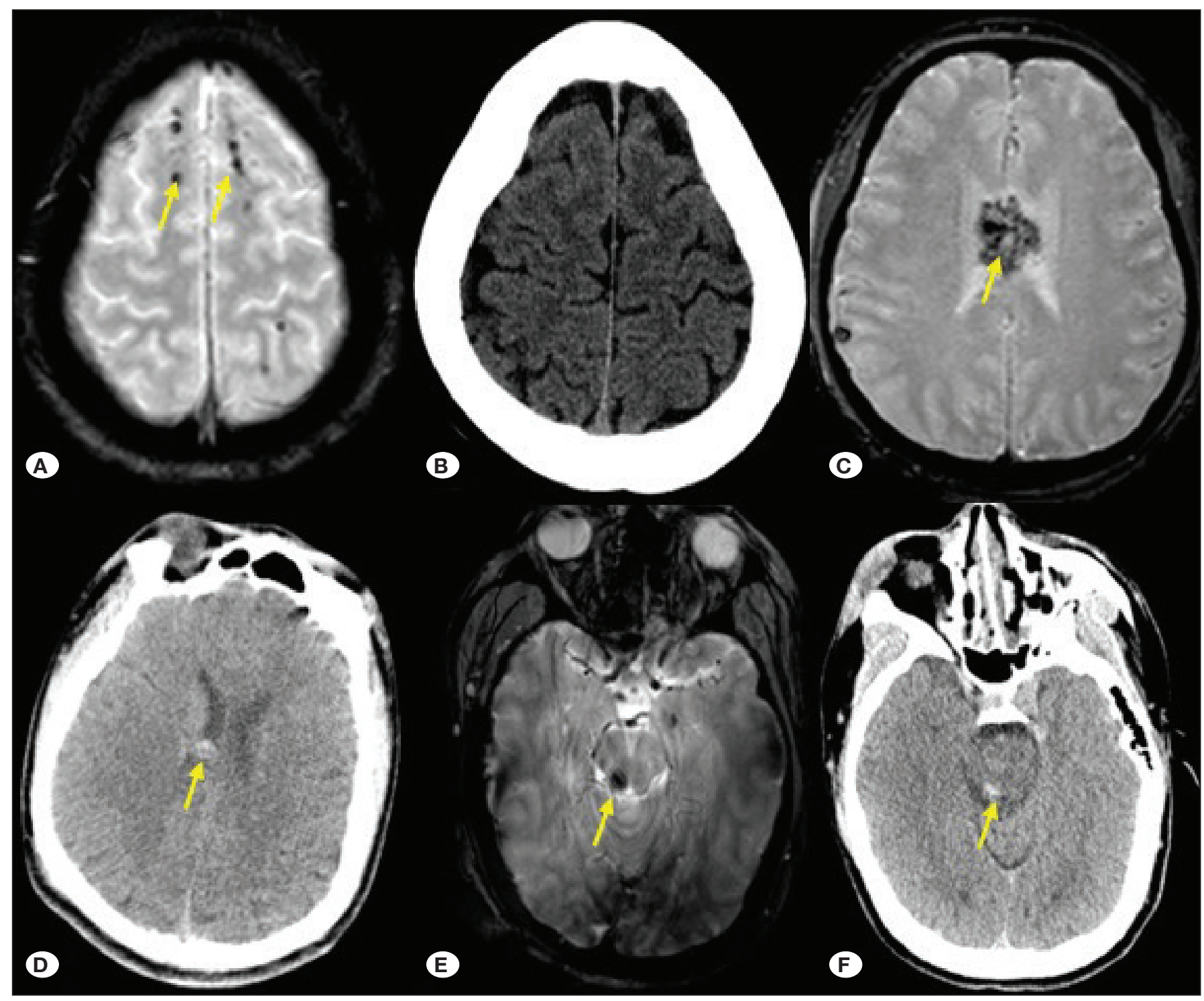

Figure 2: Radiological features of diffuse axonal injury (DAl) stages in traumatic brain injury patients. Arrows indicate DAls. A) Axial MRI showing signal intensity changes in the lobar white matter (stage I). B) No evidence of DAI was observed on CT scan. C, D) Axial CT showing a high-density hemorrhage in the right corpus callosum. Axial MRI showing a hemorrhage with swelling in the same location (stage II). E, F) Axial CT and MRI showing a small hemorrhage in the right midbrain (stage III).

CT: computed tomography, MRI: magnetic resonance imaging.

with respect to baseline characteristics: mean age (stage I: 48.1, stage II: 42.75 , stage III: $42.15, p=0.493$ ), male gender (stage I: $85 \%$ (17/20), stage II: $50 \%$ (2/4), stage III: $69.2 \%$ (9/13), $p=0.200)$, and comorbidity (stage l: $10 \%(2 / 20)$, stage II: $25 \%(1 / 4)$, stage III: $23.1 \%(3 / 13), p=0.247)$. Patient demographics and clinical characteristics are summarized in Table I.

MRI was obtained in 20 patients within a median of 4.5 days (interquartile range, 1-30) after admission. The proportion of patients who received $\mathrm{MRI}$ in each group did not differ significantly (stage I: $45 \%$ (9/20), stage II: $50 \%$ (2/4), stage III: $69.23 \%(9 / 13) ; p=0.183)$. The characteristics of DAl findings on CT or MRI are summarized in Table II.
Transfusion within 24 hours of admission (stage I: 9, stage II: 0 , stage III: $9, p=0.046$ ) and shock or cardiac arrest (stage I: 6 , stage II: 0 , stage III: $9, \mathrm{p}=0.018$ ) were significantly related to treatment outcome. The number of patients with favorable outcome (GOS 4 and 5) (stage I: 17, stage II: 4, stage III: 4) and unfavorable outcome (GOS 1, 2 and 3) (stage I: 3, stage II: 0, stage III: 9) significantly differed between groups $(p=0.002)$. Three patients underwent neurosurgery: 1 cranioplasty for depressed skull fracture in the stage I group, 1 EVD for traumatic subarachnoid hemorrhage (T-SAH) with intraventricular hemorrhage in the stage III group, and 1 decompressive craniectomy for severe brain swelling with subdural hematoma (SDH) in the stage III group. Treatment outcomes are summarized in Table III. 
To further examine the association between patient characteristics and clinical outcome, certain parameters were selected for univariate and multivariate logistic regression analysis (Table IV). Due to the small number of DAl stage IIpatients (4), we combined stage II into both I and III for analysis. The univariate analysis was as follows: stages I and II vs. III (odds ratio (OR) $15.750,95 \% \mathrm{Cl} 2.91-85.22, \mathrm{p}=0.001$ ) and stages I vs. II and III (OR 6.375, 95\% Cl 1.35-30.14, $\mathrm{p}=0.019)$, initial GCS (OR $0.828,95 \% \mathrm{Cl} 0.67-1.03, \mathrm{p}=0.086$ ), initial RTS (OR 0.624, 95\% Cl 0.38-1.01, $\mathrm{p}=0.055)$, transfusion within 24 hours of admission (OR 5.333, 95\% Cl 1.14-24.90, $\mathrm{p}=0.033)$, shock or cardiac arrest (OR 9.50, 95\% Cl 1.92$46.90, p=0.006$ ), neurosurgical operation (OR $5.238,95 \% \mathrm{Cl}$ 0.99-27.69, $\mathrm{p}=0.051$ ), T-SAH (OR7.714, 95\% Cl 1.60-37.13, $\mathrm{p}=0.011)$ and SDH (OR 8.000, 95\% Cl 1.70-37.67, $\mathrm{p}=0.009)$. In multivariate analysis using the above parameters, only DAI Stage (I and II vs. III, OR 3.806, 95\% Cl 1.50-9.69, p=0.005) and SDH (OR 7.179, 95\% Cl 1.10-46.89, $\mathrm{p}=0.040$ ) were significant.

\section{DISCUSSION}

DAl is common in patients with TBI $(12,40)$, but its prevalence with clinical outcome has rarely been reported. Several studies have shown that DAl is associated with disability, cognitive impairment, and death $(26,39,45)$. One possible reason for less interest in this field is difficulty of diagnosis in the past. In addition, it is difficult to include expired TBI patients or patients

Table I: Patient Demographics and Clinical Characteristics Stratified by DAI Stage

\begin{tabular}{|c|c|c|c|c|}
\hline & DAl stage I $(n=20)$ & DAl stage II $(n=4)$ & DAl stage III $(n=13)$ & $\mathbf{p}$ \\
\hline Age (years) & $48.1 \pm 20$ & $42.75 \pm 25.32$ & $42.15 \pm 15.69$ & 0.493 \\
\hline Sex (male/female) & $17 / 3$ & $2 / 2$ & $9 / 4$ & 0.200 \\
\hline Comorbidity & 2 & 1 & 3 & 0.247 \\
\hline $\begin{array}{l}\text { Injury mechanism } \\
\text { Motor vehicle accident } \\
\text { Pedestrian accident } \\
\text { Fall } \\
\end{array}$ & $\begin{array}{l}9 \\
5 \\
6\end{array}$ & $\begin{array}{l}2 \\
1 \\
1 \\
\end{array}$ & $\begin{array}{l}6 \\
2 \\
5 \\
\end{array}$ & 0.980 \\
\hline Initial GCS & $9.9 \pm 3.4$ & $7.5 \pm 1.29$ & $7.15 \pm 3.36$ & 0.057 \\
\hline Initial ISS & $27.75 \pm 13.69$ & $27.75 \pm 13.94$ & $32.62 \pm 14.53$ & 0.637 \\
\hline Initial RTS & $10.65 \pm 1.35$ & $10.25 \pm 1.26$ & $9.15 \pm 1.63$ & 0.026 \\
\hline $\begin{array}{l}\text { Initial vital signs } \\
\text { Mean arterial pressure }(\mathrm{mmHg}) \\
\text { Heart rate }(/ \text { minute }) \\
\text { Respiratory rate }(/ \text { minute }) \\
\text { Body temperature }\left({ }^{\circ} \mathrm{C}\right)\end{array}$ & $\begin{array}{c}86.58 \pm 22.24 \\
92.3 \pm 23.35 \\
20.6 \pm 3.07 \\
36.6 \pm 0.53\end{array}$ & $\begin{array}{c}92.58 \pm 4.18 \\
105.25 \pm 35.21 \\
28.5 \pm 11.12 \\
36.9 \pm 1.13\end{array}$ & $\begin{array}{c}80.51 \pm 26.29 \\
99.38 \pm 22.02 \\
18.08 \pm 5.72 \\
36.32 \pm 0.83\end{array}$ & $\begin{array}{l}0.458 \\
0.644 \\
0.060 \\
0.148\end{array}$ \\
\hline $\begin{array}{l}\text { Initial laboratory data } \\
\mathrm{pH} \\
\mathrm{PO}_{2}(\mathrm{mmHg}) \\
\mathrm{PCO}_{2}(\mathrm{mmHg}) \\
\text { Base excess }(\mathrm{mmEq} / \mathrm{L}) \\
\text { Bicarbonate }(\mathrm{mmEq} / \mathrm{L}) \\
\text { Hemoglobin }(\mathrm{g} / \mathrm{dL}) \\
\text { Hematocrit }(\%) \\
\text { White blood cells }\left(\mathrm{cell} / \mathrm{mm}^{3}\right) \\
\text { Platelets }\left(10^{\wedge} 3, \mathrm{~g} / \mathrm{L}\right) \\
\text { Prothrombin time }(\%) \\
\text { Sodium }(\mathrm{mmol} / \mathrm{L}) \\
\text { Glucose }(\mathrm{mg} / \mathrm{dL}) \\
\text { BUN }(\mathrm{mmol} / \mathrm{L}) \\
\text { Creatinine }(\mu \mathrm{mol} / \mathrm{L}) \\
\text { CRP }(\mathrm{mg} / \mathrm{dL}) \\
\text { Lactic acid }(\mathrm{mmol} / \mathrm{L})\end{array}$ & $\begin{array}{c}7.36 \pm 0.11 \\
115.9 \pm 45.51 \\
37.15 \pm 7.07 \\
-3.52 \pm 5.18 \\
21.42 \pm 4.19 \\
13.03 \pm 1.93 \\
39.03 \pm 5.21 \\
11825 \pm 3560.58 \\
208.4 \pm 66.94 \\
97.79 \pm 20.21 \\
140.1 \pm 3.75 \\
182.1 \pm 63.08 \\
16.05 \pm 4.55 \\
0.93 \pm 0.31 \\
1.72 \pm 3.48 \\
3.54 \pm 1.96\end{array}$ & $\begin{array}{c}7.44 \pm 0.04 \\
108.5 \pm 47.01 \\
33 \pm 8.49 \\
-1.2 \pm 2.33 \\
22.5 \pm 3.7 \\
12.63 \pm 1.33 \\
36.53 \pm 3.19 \\
12450 \pm 4282.13 \\
212.25 \pm 48.99 \\
78.93 \pm 31.67 \\
141.25 \pm 2.63 \\
118.5 \pm 23.12 \\
20.5 \pm 9 \\
1.13 \pm 0.95 \\
4.09 \pm 3.64 \\
3.18 \pm 1.75\end{array}$ & $\begin{array}{c}7.31 \pm 0.11 \\
133.15 \pm 79.71 \\
40.23 \pm 9.12 \\
-4.16 \pm 4.06 \\
19.87 \pm 5.79 \\
12.52 \pm 2.89 \\
36.66 \pm 7.86 \\
10638.46 \pm 5110.05 \\
237.15 \pm 95.87 \\
81 \pm 15.7 \\
139.31 \pm 3.82 \\
177.92 \pm 92.85 \\
21 \pm 19.89 \\
1.15 \pm 1.16 \\
2.03 \pm 4.18 \\
4.34 \pm 2.65\end{array}$ & $\begin{array}{l}0.068 \\
0.900 \\
0.335 \\
0.612 \\
0.700 \\
0.290 \\
0.779 \\
0.418 \\
0.727 \\
0.051 \\
0.755 \\
0.070 \\
0.810 \\
0.646 \\
0.325 \\
0.622\end{array}$ \\
\hline
\end{tabular}

Values shown are means \pm standard deviation. Bold numbers correspond to significant $p$ values. BUN: blood urea nitrogen, CRP: $\mathbf{C}-$ reactive protein, DAl: diffuse axonal injury, DM: diabetes mellitus, GCS: Glasgow coma scale, HTN: hypertension, ISS: injury severity score, RTS: revised trauma score. 
Kim M. et al: DAI Risk Factors and Outcome

Table II: Characteristics of DAl findings on CT or MRI

\begin{tabular}{|c|c|c|c|c|}
\hline & DAl stage I $(n=20)$ & DAl stage II $(n=4)$ & DAl stage III $(n=13)$ & $\mathbf{p}$ \\
\hline \multicolumn{5}{|l|}{ Number of DAl lesions ${ }^{*}$} \\
\hline $1-3$ & 12 & 2 & 4 & \\
\hline $4-6$ & 5 & 1 & 3 & 0.095 \\
\hline $7-9$ & 0 & 1 & 0 & \\
\hline Traumatic-subarachnoid hemorrhage & 5 & 2 & 6 & \\
\hline Intraventricular hemorrhage & 3 & 2 & 6 & \\
\hline Intracerebral hemorrhage & 3 & 1 & 3 & \\
\hline Subdural hematoma & 6 & 0 & 6 & \\
\hline Epidural hematoma & 0 & 0 & 0 & \\
\hline
\end{tabular}

*Multiple selections were available. CT: Computed tomography, DAl: diffuse axonal injury, MRI: magnetic resonance imaging.

Table III: Summary of Treatment Outcome in 37 DAI Patients

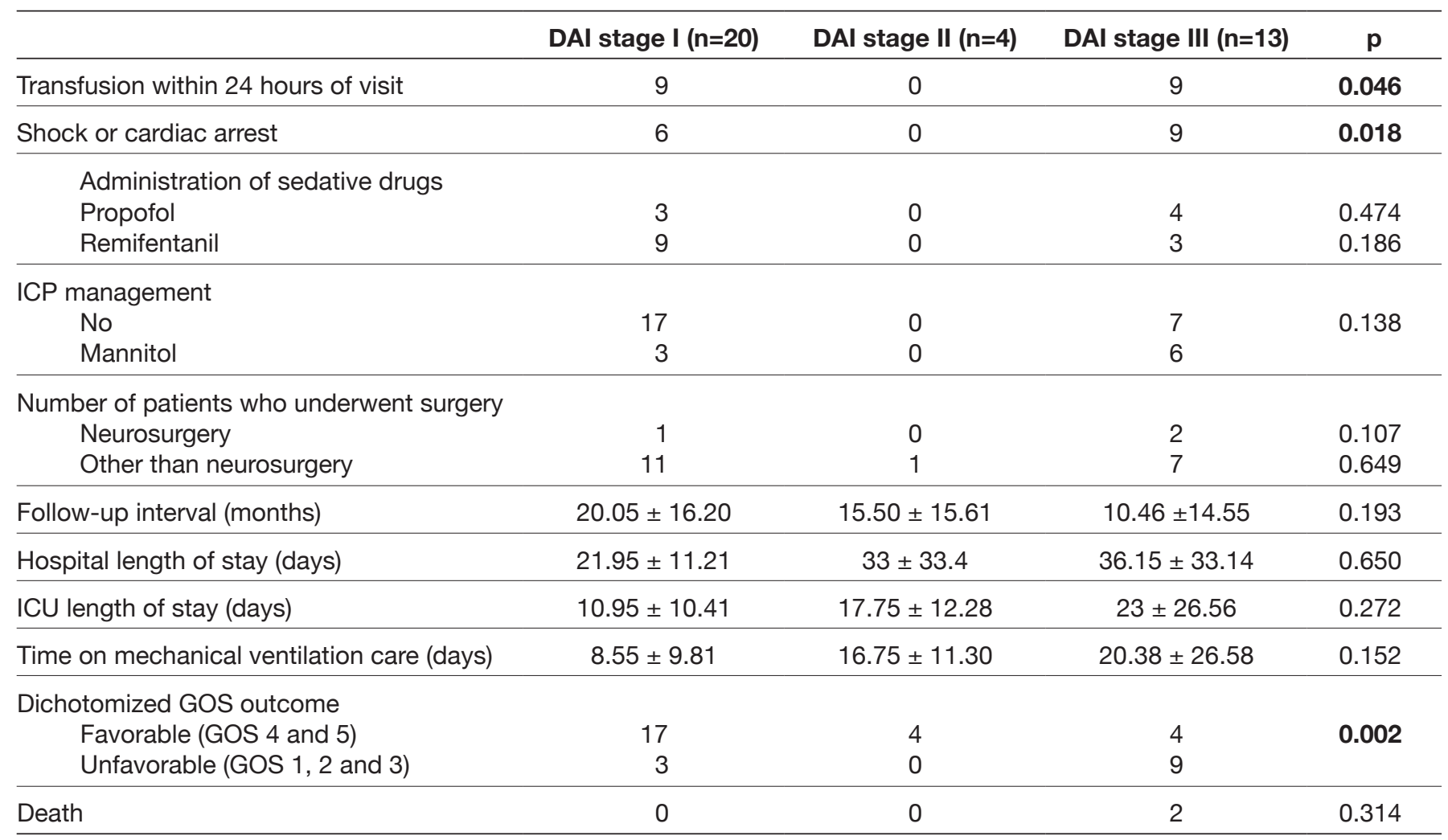

Values are shown asnumbers ormeans \pm standard deviation. Bold numbers correspond to significant $p$ values. DAl: diffuse axonal injury, GOS: Glasgow outcome scale, ICP: intracranial pressure, ICU: intensive care unit. 
Table IV: Association between Glasgow Outcome Scale (GOS) and Clinical Risk Factors Using Univariate and Multivariate Logistic Regression Models in DAI Patients

\begin{tabular}{|c|c|c|c|c|c|c|c|}
\hline & \multirow[b]{2}{*}{ Groups } & \multicolumn{3}{|c|}{ Univariate } & \multicolumn{3}{|c|}{ Multivariate* } \\
\hline & & OR & $95 \% \mathrm{Cl}$ & $\mathbf{p}$ & OR & $95 \% \mathrm{Cl}$ & $\mathbf{p}$ \\
\hline \multirow{2}{*}{ DAI Stage } & I and II & 1 & & & 1 & & \\
\hline & III & 15.750 & 2.91-85.22 & 0.001 & 3.806 & $1.50-9.69$ & 0.005 \\
\hline \multirow{2}{*}{ DAI Stage } & I & 1 & & & & & \\
\hline & II and III & 6.375 & $1.35-30.14$ & 0.019 & & & \\
\hline Initial GCS & & 0.828 & $0.67-1.03$ & 0.086 & & & \\
\hline Initial RTS & & 0.624 & $0.38-1.01$ & 0.055 & & & \\
\hline Transfusion within 24 hours of visit & & 5.333 & $1.14-24.90$ & 0.033 & & & \\
\hline Shock or cardiac arrest & & 9.500 & $1.92-46.90$ & 0.006 & & & \\
\hline Neurosurgical operation & & 5.238 & $0.99-27.69$ & 0.051 & & & \\
\hline Traumatic-subarachnoid hemorrhage & & 7.714 & $1.60-37.13$ & 0.011 & & & \\
\hline Subdural hematoma & & 8.000 & $1.70-37.67$ & 0.009 & 7.179 & $1.10-46.89$ & 0.040 \\
\hline
\end{tabular}

*Stepwise selection method was used. Bold numbers correspond to significant $p$ values. Cl: confidence interval, DAl: diffuse axonal injury, GCS: Glasgow coma scale, NS: neurological surgery, OR: odds ratio, RTS: revised trauma score.

who died before performing MRI to thoroughly evaluate DAI. However, with recent advances in neurological imaging, the diagnosis of DAI has become much more familiar to clinicians.

Generally, functional neurological damage increases linearly in clinical severity withmore advanced DAI neuropathological stage (4): higher DAI stage has been reported to correlate with worse outcome $(8,16)$. Involvement of the brainstem and corpus callosum also significantly correlates with poor clinical outcome (19). Interestingly, our study revealed that most stage I and II patients $(87.5 \%, 21 / 24)$ showed a favorable outcome, whereas high morbidity was observed in stage III patients $(69.23 \%, 9 / 13)$. This finding is contrary to prior studies that have reported generally poor outcome in DAl patients $(26,45)$. In our univariate and multivariate analyses, staging of DAI (stage I and II vs. III orstage I vs. II and III) significantly correlated with GOS. Furthermore, analysis using stage I and II vs. III (OR 15.750) showed a much stronger correlation compared to stage I vs. II and III (OR 6.375). We may infer from this analysis that stage II is more clinically correlated to I rather than III. A similar result was observed in another study that reported DAI is not a clinical risk factor if the lesion is not locatedin the brainstem (40). In that study, when brainstem lesions were excluded from the analysis, DAl did not show a worse outcome. Therefore, the worse outcome observed in DAI patients was likely due tostage III cases, not stage I or II.

It is clinically important to distinguish stages of DAI in order to predict patient outcome. We found no demographic differences between DAl stages in this study. In addition, other factors, including vital signs and initial laboratory data, showed no significant differences between DAl stages, except for RTS. This is an interesting result, as advanced age has been traditionally associated with poor outcome in TBI patients (41).We must be aware that DAl patients may deteriorate urgently, as transfusion within 24 hours of admission was strongly related to clinical outcome (OR 5.333, $\mathrm{p}=0.033$ ). Hence, prompt and careful attention should be given to all patients, even those with low DAl stage or normal blood laboratory analysis results.

The relationship between initial GCS and clinical outcome is uncertain in DAl patients. Low GCS scores have been correlated with unfavorable outcome in some studies $(43,47)$, but notin another (40). In ours, although GCS was lower in stage III patients, this finding only approached significance $(p=0.057)$. However, RTS was significantly lower $(p=0.026)$. Hence, when such clinical findings are evident in a TBI patient and the cranial CT does not account for decreased level of consciousness, we could anticipate that the injury is stage III DAland should be promptly managed with caution as poor outcome is likely.

Hypotension and transfusion are well known to be responsible for poor outcome in DAI patients $(5,7,23)$. In our univariate analysis, shock or cardiac arrest, and transfusion within 24 hours of admission were significantly associated with poor outcome. These factors must be scrutinized since the injured brain is susceptible to hypotension; hypotension combined with shock, cardiac arrest, or transfusion results in worse outcome $(10,22)$. Given that these findings are correctable, theys hould be promptly managed to improve outcome.

TBI patients often present with other brain injuries associated with DAI $(7,20,34)$. In our study, -SAH $(p=0.011)$ and $\mathrm{SDH}(p=0.009)$ strongly correlated with poor outcome, in accordance with previous studies $(7,33,37)$. We presume that this association is due to the severity of trauma and the resulting high acceleration-deceleration forces that cause DAI 
(7). These combined traumatic brain injuries may lead the physician to misinterpret decreased level of consciousness, leading to unnecessary surgery. Therefore, we strongly recommend prompt MRI that includes hemorrhage-sensitive sequences for TBI patients whose CT scan and level of consciousness do not clearly correlate.

CT has many advantages in detecting TBI; it is simple, fast, and convenient. However, CT is not sensitive for diagnosing DAI, particularly in the brainstem $(21,25)$. CT is also fairly limited in the ability to detect lesions in the white matter or corpus callosum. Therefore, $\mathrm{MRI}$ is required to properly diagnose stage III DAI $(2,11,12)$. DWI is sensitive for intraand extracellular edema, and T2-weighted GRE is sensitive to detect hemorrhages in the white matter, corpus callosum, and brainstem $(24,39,46)$. However, MRI cannot be routinely performed in all TBI patients. Although MRI has prognostic value with superior discretion (31) compared with CT (29), it is often difficult to perform in the early phase after trauma (31). Consequently, the decision to obtain MRI with the appropriate sequences within atimely interval is crucial. In our study, the median interval between trauma and MRI was 4.5 days. Hemorrhagic and non-hemorrhagic DAl-associated lesions on $\mathrm{MRI}$ are known to diminish over time, and the value of MRI may vanish when performed late $(30,32)$. A recent study involving 30 DAl patients concluded that MRI should be performed within the first week of injury for a more reliable prognosis (1). The optimal timing for MRI in DAl patients is unknown, however, a shorter interval to imaging can achieve a more accurate and rapid diagnosis and improve clinical outcome.

The limitations of this study should be noted. First, it was retrospective in nature and performed in a single institution. Second, our hospital serves as a referral center for the treatment of highly complex cases, which limits the generalization of our findings. Third, due to the low prevalence of stage II DAI patients, the statistical analyses might have been underpowered and all possible significant factors may not have been identified. Fourth, despite the large group of patients initially included (992 patients), the small number of patients with DAl actually studied may have over whelmed the discriminatory properties of the dichotomized GOS. Fifth, MRI was not available in all patients, and for those who received $\mathrm{MRI}$, the interval between trauma and MRI varied. MRI findings may have affected diagnosis and led tomore effective management in DAI patients. Nevertheless, our study showed that stage III DAI with SDH results inpoor clinical outcome, whereas a favorable outcome was observed in stages I and II. The strength of this study is that it directly compared 3 DAI stages using radiologic imaging as well as demographic data and clinical factors, which previous studies have lacked.

\section{- CONCLUSION}

Analyzing the risks factors associated with DAI is essential to develop standardized therapy and evaluate treatment outcome. This study concluded that stage III DAI and SDH were risk factors related to poor clinical outcome. In addition, we found that patients with stages I and II DAI exhibited a much better prognosis than expected. Therefore, early diagnosis of stage III is key to improve clinical outcome. The optimal timing of MRI should be investigated in future studies to further elucidate outcome in DAl patients. As the GOS is relatively simple, more detailed and functional outcome measures in volving the neurological examination are essential in a new outcome scale to more precisely predict DAI outcome.

\section{REFERENCES}

1. Abu Hamdeh S, Marklund N, Lannsjo M, Howells T, Raininko $\mathrm{R}$, Wikstrom J, Enblad P: Extended anatomical grading in diffuse axonal injury using MRI: Hemorrhagic lesions in the substantia nigra and mesencephalic tegmentum indicate poor long-term outcome. J Neurotrauma 34:341-352, 2017

2. Adams JH, Doyle D, Ford I, Gennarelli TA, Graham DI, McLellan DR: Diffuse axonal injury in head injury: Definition, diagnosis and grading. Histopathology 15:49-59, 1989

3. Adams JH, Doyle D, Graham DI, Lawrence AE, McLellan DR: Diffuse axonal injury in head injuries caused by a fall. Lancet 2:1420-1422, 1984

4. Adams JH, Graham DI, Murray LS, Scott G: Diffuse axonal injury due to nonmissile head injury in humans: An analysis of 45 cases. Ann Neurol 12:557-563, 1982

5. Alberico AM, Ward JD, Choi SC, Marmarou A, Young HF: Outcome after severe head injury. Relationship to mass lesions, diffuse injury, and ICP course in pediatric and adult patients. J Neurosurg 67:648-656, 1987

6. Champion HR, Sacco WJ, Copes WS, Gann DS, Gennarelli TA, Flanagan ME: A revision of the trauma score. J Trauma 29:623-629, 1989

7. Chelly H, Chaari A, Daoud E, Dammak H, Medhioub F, Mnif J, Hamida CB, Bahloul M, Bouaziz M: Diffuse axonal injury in patients with head injuries: An epidemiologic and prognosis study of 124 cases. J Trauma 71:838-846, 2011

8. Chew BG, Spearman CM, Quigley MR, Wilberger JE: The prognostic significance of traumatic brainstem injury detected on T2-weighted MRI. J Neurosurg 117:722-728, 2012

9. Elf K, Nilsson P, Enblad P: Outcome after traumatic brain injury improved by an organized secondary insult program and standardized neurointensive care. Crit Care Med 30:21292134, 2002

10. Eum SW, Lim DJ, Kim BR, Cho TH, Park JY, Suh JK, Lee KC, Lee HK: Prognostic factors in patients with diffuse axonal injury. J Korean Neurosurg Soc 27:1668-1674, 1998

11. Gennarelli TA, Thibault LE, Adams JH, Graham DI, Thompson CJ, Marcincin RP: Diffuse axonal injury and traumatic coma in the primate. Ann Neurol 12:564-574, 1982

12. Gentry LR: Imaging of closed head injury. Radiology 191:1-17, 1994

13. Gentry LR, Godersky JC, Thompson B: MR imaging of head trauma: Review of the distribution and radiopathologic features of traumatic lesions. AJR Am J Roentgenol 150:663672,1988

14. Grados MA, Slomine BS, Gerring JP, Vasa R, Bryan N, Denckla MB: Depth of lesion model in children and adolescents with moderate to severe traumatic brain injury: Use of SPGR MRI to predict severity and outcome. J Neurol Neurosurg Psychiatry 70:350-358, 2001 
15. Greenspan L, McLellan BA, Greig H: Abbreviated injury scale and injury severity score: A scoring chart. J Trauma 25:60-64, 1985

16. Hilario A, Ramos A, Millan JM, Salvador E, Gomez PA, Cicuendez M, Diez-Lobato R, Lagares A: Severe traumatic head injury: Prognostic value of brain stem injuries detected at MRI. AJNR Am J Neuroradiol 33:1925-1931, 2012

17. Jennett $B$, Bond $M$ : Assessment of outcome after severe brain damage. Lancet 1:480-484, 1975

18. Jeong HW, Choi SW, Youm JY, Lim JW, Kwon HJ, Song SH: Mortality and epidemiology in 256 cases of pediatric traumatic brain injury: Korean Neuro-Trauma Data Bank System (KNTDBS) 2010-2014. J Korean Neurosurg Soc 60:710-716, 2017

19. Kampfl A, Schmutzhard E, Franz G, Pfausler B, Haring HP, Ulmer H, Felber S, Golaszewski S, Aichner F: Prediction of recovery from post-traumatic vegetative state with cerebral magnetic-resonance imaging. Lancet 351:1763-1767, 1998

20. Lagares A, Ramos A, Alday R, Ballenilla F, Perez-Nunez A, Arrese I, Alen JF, Pascual B, Kaen A, Gomez PA, Lobato RD: Magnetic resonance in moderate and severe head injury: Comparative study of CT and MR findings. Characteristics related to the presence and location of diffuse axonal injury in MR. Neurocirugia (Astur) 17:105-118, 2006

21. Lagares A, Ramos A, Perez-Nunez A, Ballenilla F, Alday R, Gomez PA, Kaen A, Lobato RD: The role of MR imaging in assessing prognosis after severe and moderate head injury. Acta Neurochir (Wien) 151:341-356, 2009

22. Lee HS, Lee KS, Bae HG, Yun IG, Lee IS: Systemic insults in the early death after head injury. J Korean Neurosurg Soc 19:1101-1106, 1990

23. Levi L, Guilburd JN, Lemberger A, Soustiel JF, Feinsod M: Diffuse axonal injury: Analysis of 100 patients with radiological signs. Neurosurgery 27:429-432, 1990

24. Li XY, Feng DF: Diffuse axonal injury: Novel insights into detection and treatment. J Clin Neurosci 16:614-619, 2009

25. Lobato RD, Gomez PA, Alday R, Rivas JJ, Dominguez J, Cabrera A, Turanzas FS, Benitez A, Rivero B: Sequential computerized tomography changes and related final outcome in severe head injury patients. Acta Neurochir (Wien) 139:385391, 1997

26. Maas Al, Stocchetti N, Bullock R: Moderate and severe traumatic brain injury in adults. Lancet Neurol 7:728-741, 2008

27. Mannion RJ, Cross J, Bradley P, Coles JP, Chatfield D, Carpenter A, Pickard JD, Menon DK, Hutchinson PJ: Mechanism-based MRI classification of traumatic brainstem injury and its relationship to outcome. J Neurotrauma 24:128135, 2007

28. Marquez de la Plata C, Ardelean A, Koovakkattu D, Srinivasan P, Miller A, Phuong V, Harper C, Moore C, Whittemore A, Madden C, Diaz-Arrastia R, Devous Sr M: Magnetic resonance imaging of diffuse axonal injury: Quantitative assessment of white matter lesion volume. J Neurotrauma 24: 591-598, 2007
29. Marshall LF, Marshall SB, Klauber MR, Van Berkum Clark M, Eisenberg H, Jane JA, Luerssen TG, Marmarou A, Foulkes MA: The diagnosis of head injury requires a classification based on computed axial tomography. J Neurotrauma 9 Suppl 1:S287292, 1992

30. Messori A, Polonara G, Mabiglia C, Salvolini U: Is haemosiderin visible indefinitely on gradient-echo MRI following traumatic intracerebral haemorrhage? Neuroradiology 45:881886, 2003

31. Moen KG, Brezova V, Skandsen T, Haberg AK, Folvik M, Vik A: Traumatic axonal injury: the prognostic value of lesion load in corpus callosum, brain stem, and thalamus in different magnetic resonance imaging sequences. J Neurotrauma 31: 1486-1496, 2014

32. Moen KG, Skandsen T, Folvik M, Brezova V, Kvistad KA, Rydland J, Manley GT, Vik A: A longitudinal MRI study of traumatic axonal injury in patients with moderate and severe traumatic brain injury. J Neurol Neurosurg Psychiatry 83:11931200, 2012

33. Parchani A, El-Menyar A, Al-Thani H, El-Faramawy A, Zarour A, Asim M, Latifi R: Traumatic subarachnoid hemorrhage due to motor vehicle crash versus fall from height: A 4-year epidemiologic study. World Neurosurg 82:e639-644, 2014

34. Paterakis K, Karantanas AH, Komnos A, Volikas Z: Outcome of patients with diffuse axonal injury: The significance and prognostic value of MRI in the acute phase. J Trauma 49:10711075, 2000

35. Pierallini A, Pantano P, Fantozzi LM, Bonamini M, Vichi R, Zylberman R, Pisarri F, Colonnese C, Bozzao L: Correlation between MRI findings and long-term outcome in patients with severe brain trauma. Neuroradiology 42:860-867, 2000

36. Roozenbeek B, Maas AI, Menon DK: Changing patterns in the epidemiology of traumatic brain injury. Nat Rev Neurol 9:231236, 2013

37. Sahuquillo-Barris J, Lamarca-Ciuro J, Vilalta-Castan J, RubioGarcia E, Rodriguez-Pazos M: Acute subdural hematoma and diffuse axonal injury after severe head trauma. J Neurosurg 68:894-900, 1988

38. Schaefer PW, Huisman TA, Sorensen AG, Gonzalez RG, Schwamm LH: Diffusion-weighted MR imaging in closed head injury: High correlation with initial glasgow coma scale score and score on modified Rankin scale at discharge. Radiology 233:58-66, 2004

39. Scheid R, Walther K, Guthke T, Preul C, von Cramon DY: Cognitive sequelae of diffuse axonal injury. Arch Neurol 63:418-424, 2006

40. Skandsen T, Kvistad KA, Solheim O, Strand IH, Folvik M, Vik A: Prevalence and impact of diffuse axonal injury in patients with moderate and severe head injury: A cohort study of early magnetic resonance imaging findings and 1-year outcome. J Neurosurg 113:556-563, 2010

41. Stawicki SP, Wojda TR, Nuschke JD, Mubang RN, Cipolla J, Hoff WS, Hoey BA, Thomas PG, Sweeney J, Ackerman D, Hosey J, Falowski S: Prognostication of traumatic brain injury outcomes in older trauma patients: A novel risk assessment tool based on initial cranial CT findings. Int J Crit IIIn Inj Sci 7:23-31, 2017 
42. Teasdale G, Jennett B: Assessment of coma and impaired consciousness. A practical scale. Lancet 2:81-84, 1974

43. Vieira RC, Paiva WS, de Oliveira DV, Teixeira MJ, de Andrade AF, de Sousa RM: Diffuse axonal injury: Epidemiology, outcome and associated risk factors. Front Neurol 7:178, 2016

44. Wedekind C, Hesselmann V, Lippert-Gruner M, Ebel M: Trauma to the pontomesencephalic brainstem-a major clue to the prognosis of severe traumatic brain injury. $\mathrm{Br} \mathrm{J}$ Neurosurg 16:256-260, 2002

45. Weiss N, Galanaud D, Carpentier A, Naccache L, Puybasset L: Clinical review: Prognostic value of magnetic resonance imaging in acute brain injury and coma. Crit Care 11:230, 2007
46. Xu J, Rasmussen IA, Lagopoulos J, Haberg A: Diffuse axonal injury in severe traumatic brain injury visualized using highresolution diffusion tensor imaging. J Neurotrauma 24:753765, 2007

47. Yanagawa Y, Sakamoto T, Takasu A, Okada Y: Relationship between maximum intracranial pressure and traumatic lesions detected by $\mathrm{T} 2^{*}$-weighted imaging in diffuse axonal injury. $\mathrm{J}$ Trauma 66:162-165, 2009

48. Yanagawa Y, Tsushima Y, Tokumaru A, Un-no Y, Sakamoto T, Okada Y, Nawashiro H, Shima K: A quantitative analysis of head injury using $\mathrm{T}^{*}$-weighted gradient-echo imaging. J Trauma 49:272-277, 2000 